\title{
St-Cirgues-la-Loutre - Le Bourg
}

\section{Henri Pigeyre}

URL : http://journals.openedition.org/adlfi/5175

ISSN : 2114-0502

Éditeur

Ministère de la culture

\section{Référence électronique}

Henri Pigeyre, "St-Cirgues-la-Loutre - Le Bourg », ADLFI. Archéologie de la France - Informations [En ligne], Limousin, mis en ligne le 01 mars 2006, consulté le 19 avril 2019. URL : http:// journals.openedition.org/adlfi/5175

Ce document a été généré automatiquement le 19 avril 2019

(c) Ministère de la Culture et de la Communication, CNRS 


\title{
St-Cirgues-la-Loutre - Le Bourg
}

\author{
Henri Pigeyre
}

Identifiant de l'opération archéologique : 2642

Date de l'opération : 2006 (SD)

1 Le souterrain est situé dans le centre du bourg sous la place de l'église. Il a été découvert en 1932 lors de l'électrification du village (trou de poteau). Il a été inventorié lors de la prospection inventaire de 2004 de cette commune. Une demande de sondage a été accordée du 15 janvier au 30 juin 2006 sur une partie de la structure.

2 Le souterrain est creusé dans le granite et l'accès se fait par une échelle métallique scellée à l'emplacement du trou de poteau de découverte. Il se compose de deux parties distinctes :

3 - la première : rectiligne, d'une vingtaine de mètres de long et de gros diamètre $(2,2 \mathrm{~m})$. Cette partie du souterrain possède une banquette de chaque côté qui devait servir de support à un plancher pour isoler les denrées alimentaires du sol très humide. L'extrémité sud-ouest est fermée par des remblais contre lesquels s'accumule temporairement l'eau de ruissellement de la galerie.

$4 \quad$ - la seconde : une galerie de faible section très tortueuse remonte vers la surface. Cette petite galerie partiellement remblayée a fait l'objet de ces travaux de sondage archéologique. D'après les habitants du bourg, cette galerie débouche dans l'église actuelle, dans une des deux chapelles adjacentes. Les conditions de fouille sont difficiles à cause de la section très petite de la galerie ( $1 \mathrm{~m}$ de haut par $0,6 \mathrm{~m}$ de large). La méthode de travail est par tranche d'environ cinquante centimètres de long sur toute la largeur de la galerie avec étayage du front ainsi créé (pour des raisons de sécurité). Toutes les terres ont été tamisées à sec au fur et à mesure du chargement des seaux pour évacuer les remblais vers la grande galerie (ce qui a permis de localiser le matériel découvert avec une grande précision). La fouille s'est poursuivie sur une dizaine de mètres de long avant de déboucher en surface sur la place de l'église. Cette place, qui était l'ancien cimetière du 
village jusque vers les années 1900, avait été décaissée pour en faire la place actuelle. Sur le cadastre "napoléonien » (1841) on trouve à l'intérieur du cimetière une très petite parcelle $(6 \mathrm{~m} \times 6 \mathrm{~m})$ dans laquelle sort le souterrain. Un sondage sur un des angles de cette parcelle n'a pas permis de trouver des restes de construction ni de trou de poteau. Par contre, une tombe taillée directement dans le granite a été mise au jour. Elle possède une loge céphalique et il faudrait étendre la fouille pour comprendre la zone.

5 La sortie du souterrain s'effectue par des marches taillées dans le granite, quasiment intactes et à peine usées. Une construction en bois a été immédiatement réalisée pour protéger temporairement cette structure.

6 La stratigraphie montre quatre couches successives (de I à IV). La couche I (la plus ancienne) et la couche II sont quasiment stériles. La couche III, très charbonneuse, contient tout le matériel découvert. De très nombreux ossements ont été trouvés et une étude par Christian Vallet (INRAP) montre la présence de restes d'os d'animaux (64\%) et de restes humains ( $36 \%$ avec une très forte proportion d'os de fotus et de nourrissons). Ce fait est très curieux, le clergé ne permettait pas d'inhumer les enfants non baptisés (les fœtus en particulier) en terre consacrée.

7 Des centaines de tessons de verre ont été récoltés avec quelques morceaux de cols et de fonds de vase en verre soufflé très fins. Leur origine demeure inconnue et semble très nettement antérieure aux premières verreries de la vallée de La Cère (toute proche).

8 Vingt et une pièces de monnaie (cuivre et argent) ont été découvertes et identifiées par D. Dussot (SRA). Elles ont été frappées entre 1208 et 1355 et proviennent d'un peu toute la France.

9 Quelques tessons classiques de types « oules » en poterie grossière ont été récoltés et une cruche exceptionnelle (Fig. $\mathrm{n}^{\circ} 1$ : Cruche anthropomorphe), vernissée à l'extérieur, faisant partie probablement des poteries très décorées du XIV ${ }^{e} s$. Elle est décorée de chevrons bicolores sur la panse et une tête (humaine?) au col. Il reste de cette partie une oreille, un œil, le nez et la bouche démesurée avec ses lèvres ligaturées. Cette poterie anthropomorphe a fait l'objet de nombreuses recherches pour trouver son origine mais sans résultat pour l'instant (Angleterre, Saintonge, Rouennais, Sud-Ouest, Nord, etc.).

Un tamisage-flottation sur un échantillon de la couche III a été étudié par Anne Bouchette dans le cadre du PCR. Il a permis de mettre en évidence des restes de blé nu et de rachis de seigle et d'orge.

11 La couche IV est quasiment stérile et contient dans une argile marron de nombreux morceaux de chaux qui correspondent probablement à la construction de l'église actuelle vers 1550. Les sédiments de la couche III semblent provenir de l'incendie d'une construction située dans le cimetière du village et qui masquait l'entrée du souterrain. Cet édifice contenait un matériel exceptionnel des environs du XIV ${ }^{e}$ s. et postérieur à la période d'utilisation du souterrain. Ce bâtiment devait être en bois (très peu de pierre trouvée en sondage) et couvert en lauze (nombreux fragments et une lauze entière découverts).

Cet édifice pourrait être une chapelle ou une ancienne église de Saint-Cirgues-la-Loutre. Les textes décrivent une église antérieure à l'église actuelle, construite à cheval sur un chemin, en bordure du cimetière et détruite vers 1720 pour la construction du clocher actuel. Il est à noter que ces écrits ne correspondent pas tout à fait à ce qui a été découvert dans ce sondage. 


\section{ANNEXES}

Fig. $\mathrm{n}^{\circ} 1$ : Cruche anthropomorphe

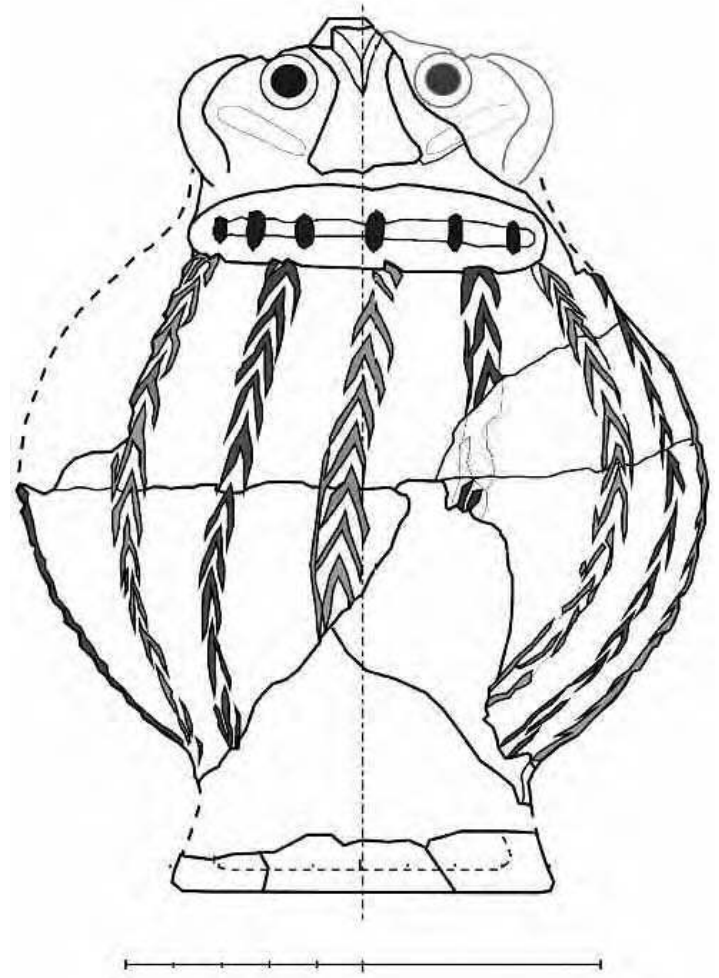

Auteur(s) : Pigeyre, Henri (BEN). Crédits : Pigeyre, Henri (2006)

\section{INDEX}

operation Sondage (SD)

Index chronologique : Moyen Âge

Thèmes : cadastre, céréale, cimetière paroissial, cruche, édifice, église, galerie, lauze, monnaie, ossement animal, ossement humain, sources écrites, souterrain, stratigraphie, tombeau, trou de poteau, verrerie

Index géographique : Limousin, Corrèze (19), Saint-Cirgues-la-Loutre

\section{AUTEURS}

HENRI PIGEYRE

BEN 